\title{
A 14-year dataset of in situ glacier surface velocities for a tidewater and a land-terminating glacier in Livingston Island, Antarctica
}

\author{
Francisco Machío ${ }^{1}$, Ricardo Rodríguez-Cielos ${ }^{2}$, Francisco Navarro ${ }^{3}$, Javier Lapazaran $^{3}$, and \\ Jaime Otero ${ }^{3}$ \\ ${ }^{1}$ Escuela Superior de Ingeniería y Tecnología, Universidad Internacional de La Rioja (UNIR), Calle Almansa, \\ 101, 28040 Madrid, Spain \\ ${ }^{2}$ Departamento de Señales, Sistemas y Radiocomunicaciones, ETSI de Telecomunicación, \\ Universidad Politécnica de Madrid, Av. Complutense, 30, 20040 Madrid, Spain \\ ${ }^{3}$ Departamento de Matemática Aplicada a las Tecnologías de la Información y las Comunicaciones, \\ ETSI de Telecomunicación, Universidad Politécnica de Madrid, Av. Complutense, 30, 20040 Madrid, Spain
}

Correspondence to: Francisco Machío (francisco.machio@unir.net)

Received: 19 April 2017 - Discussion started: 8 May 2017

Revised: 25 August 2017 - Accepted: 30 August 2017 - Published: 9 October 2017

\begin{abstract}
We present a 14-year record of in situ glacier surface velocities determined by repeated global navigation satellite system (GNSS) measurements in a dense network of 52 stakes distributed across two glaciers, Johnsons (tidewater) and Hurd (land-terminating), located on Livingston Island, South Shetland Islands, Antarctica. The measurements cover the time period 2000-2013 and were collected at the beginning and end of each austral summer season. A second-degree polynomial approximation is fitted to each stake position, which allows estimating the approximate positions and associated velocities at intermediate times. This dataset is useful as input data for numerical models of glacier dynamics or for the calibration and validation of remotely sensed velocities for a region where very scarce in situ glacier surface velocity measurements have been available so far. The link to the data repository is as follows: http://doi.pangaea.de/10.1594/PANGAEA.846791.
\end{abstract}

\section{Introduction}

In situ measured glacier surface velocities are an important source of information for the study of glacier dynamics. The strain field is defined in terms of velocity gradients, and the stresses are defined in terms of strains through the constitutive relationship (most often Nye's generalization of Glen's flaw law; e.g. Cuffey and Paterson, 2010, Sect. 3). The velocity field gradients are thus indicative of observed deformation patterns such as folding or foliation, and damage expressions such as fracturing, faulting, and crevassing (Hambrey and Lawson, 2000; Ximenis et al., 2000). Furthermore, observed surface velocities can give an insight into basal conditions. In particular, they have been used for a long time to infer basal drag (e.g. van der Veen and Whillans, 1989; Hooke et al., 1989).
Observed surface velocities are commonly used as input data for numerical models. In theory, they could be directly used as Dirichlet boundary conditions at the glacier surface for the velocity field. However, the usual practice is to impose a traction-free boundary (i.e. Neumann conditions) at the glacier surface, and the velocities are used instead for tuning the model's free parameters, such as the viscosity coefficient (ice hardness) in the constitutive relationship or the basal friction coefficient in the sliding law. Some models have treated these coefficients as constant in space (e.g. Hanson, 1995; Martín et al., 2004; Otero et al., 2010). Recently, it is becoming more and more common to establish the viscosity and/or the basal friction coefficients as functions of position. This is done by means of inversion procedures that heavily rely on observed velocities at the glacier surface. For instance, in the method introduced by Arthern and Gudmunds- 
son (2010) and modified by Jay-Allemand et al. (2011), the surface velocities are used to solve the Dirichlet problem involved in the inverse Robin problem solving for the viscosity or basal friction coefficients. However, these inversion procedures require a large amount of measured velocities, which are seldom available from in situ measurements and thus require the use of remotely sensed velocities, such as differential interferometric synthetic-aperture radar (D-InSAR), SAR offset tracking, or SAR coherence tracking velocities (e.g. Strozzi et al., 2002; Rignot and Kanagaratnam, 2006; Joughin et al., 2010; Wuite et al., 2015). But even in these cases in situ measured glacier velocities are still of wide interest, since they provide a means for the calibration and validation of remotely sensed velocities (e.g. Strozzi et al., 2008; Schellenberger et al., 2015). This is of interest in view of the recent efforts to derive time series for regional or global icevelocity fields such as those involved in the MEaSUREs program (https://nsidc.org/data/nsidc-0484/versions/2, accessed on 7 May 2017), the GoLIVE project (https://nsidc.org/data/ golive, accessed on 7 May 2017), and the ENVEO CryoPortal (http://cryoportal.enveo.at/, accessed on 7 May 2017).

In this paper, we present a 14 -year record of in situ glacier surface velocities determined by repeated global navigation satellite system (GNSS) measurements in a dense network of stakes on two glaciers, Johnsons and Hurd, located on Livingston Island, South Shetland Islands (Fig. 1). These islands, located off the north-western tip of the Antarctic Peninsula, previously had a scarce record of in situ velocity observations, which included measurements in the late 1980s on Nelson Island (Ren Jiaven et al., 1995), earlier measurements in the late 1990s on Johnsons Glacier (Ximenis et al., 1999), and measurements in the Arctowski Icefield, the Bellingshausen Dome, and the Central Dome of King George Island between 1999/2000 and 2008/09 (Blindow et al., 2010; Rückamp et al., 2010, 2011). Such in situ velocity measurements are critical for the validation of the estimates of remote-sensor-based studies of ice discharge in the region such as those by Osmanoğlu et al. $(2013,2014)$ for King George and Livingston islands (the present dataset has in fact been used in the latter paper with such purposes), as well as for tuning free parameters of glacier dynamics models, as done by Martín et al. (2004) and Otero et al. (2010) using an earlier (and shorter) version of the dataset presented. An added interest of the presented velocity record is that it corresponds to both a tidewater glacier and a landterminating glacier, two glacier types that are typical in this region but very different in dynamical behaviour.

\section{Geographical setting}

Our study area is Hurd Peninsula $\left(62^{\circ} 39-42^{\prime} \mathrm{S}, 60^{\circ} 19\right.$ $25^{\prime} \mathrm{W}$ ), located in the south of Livingston Island, South Shetland Archipelago, Antarctica. This peninsula is the setting of Juan Carlos I Station (JCI), which provided the logistic sup-

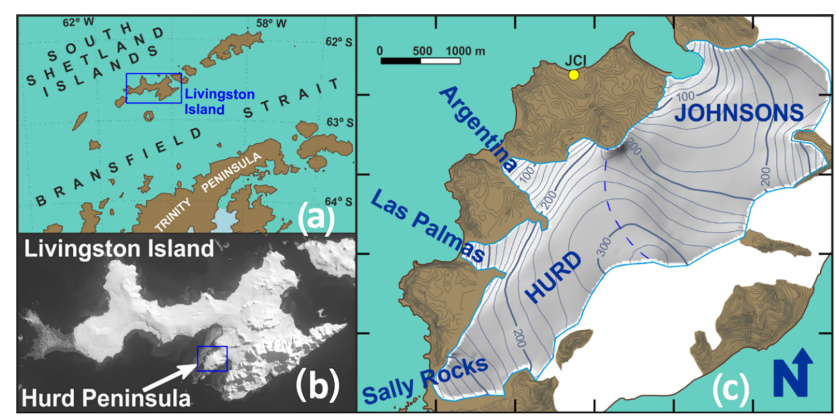

Figure 1. (a) Location of Livingston Island in the South Shetland Archipelago. (b) Location of Hurd Peninsula on Livingston Island (orthophoto generated from SPOT 1991 image by Universitat de Barcelona and Institut Cartogràfic de Catalunya, 1992). (c) Location and surface elevation map of Hurd and Johnsons glaciers, Hurd Peninsula, Livingston Island. The dashed blue line indicates the ice divide separating Hurd and Johnsons glaciers. Elevations and outline are based on a survey during summer 1998/99 and 2000/01. The yellow dot shows the position of Juan Carlos I Station (JCI).

port for our fieldwork (Fig. 1). Hurd Peninsula is covered by an ice cap that extends over an area of about $13.5 \mathrm{~km}^{2}$ and spans an altitude range from sea level to about $370 \mathrm{ma}$ a.s.l. It is partly surrounded by mountains ranging from 250 to $400 \mathrm{~m}$ in height.

This ice cap can be divided into two main glacier systems. The first main unit is Johnsons Glacier, a tidewater glacier, mostly flowing north-westwards, terminating at a $50 \mathrm{~m}$ height calving front of which just a few metres (typically $<10 \mathrm{~m}$ ) are submerged. This calving front extends approximately $500-600 \mathrm{~m}$ along the coast. The second main unit is Hurd glacier, flowing mostly south-westwards and terminating on land, with three main lobes, named Sally Rocks (flowing south-westwards), Las Palmas (flowing westwards) and Argentina (flowing north-westwards). There are three additional smaller basins, all flowing eastwards to False Bay, which were excluded from this study because they contain heavily crevassed icefalls which prevent safe field measurements.

The local ice divide separating Johnsons and Hurd lies between 250 and 330 ma.s.l. (Fig. 1c). Hurd Glacier has an average surface slope of about $3^{\circ}$, though the small westward flowing glacier tongues Argentina and Las Palmas are steeper, around $13^{\circ}$. Typical surface slopes for Johnsons Glacier range between $10^{\circ}$ in its northern areas and $6^{\circ}$ in the southern ones.

The Hurd Peninsula ice cap is a polythermal ice mass, showing an upper layer of cold ice, several tens of metres thick, in the ablation zone. This layer is uniformly distributed in Hurd Glacier and shows a more irregular distribution for Johnsons Glacier (Navarro et al., 2009). In the snouts of Hurd Glacier (in Sally Rocks area) and its side lobes Argentina and Las Palmas, where the glacier thickness tapers to zero, the cold ice layer extends down to bedrock, so the glacier is 
frozen to the bed, implying a compressional stress regime. In contrast, the area close to the Johnsons calving front shows the extensional stress regime characteristic of the terminus of tidewater glaciers (Molina et al., 2007; Navarro et al., 2009; Otero et al., 2010).

The average ice thickness of the joint Hurd-Johnsons, determined from ground-penetrating radar data in 2000/01, was $93.6 \pm 2.5 \mathrm{~m}$, with maximum values about $200 \mathrm{~m}$ in the accumulation area of Hurd Glacier and only about $160 \mathrm{~m}$ in Johnsons Glacier (Navarro et al., 2009). The bed of Johnsons Glacier is smooth, with altitudes decreasing towards the ice front, where glacier bed elevation is slightly below sea level (typically $<10 \mathrm{~m}$ ). The Hurd Glacier bed, however, is more irregular, with a clear overdeepening in the thickest ice area, close to the head of Argentina side lobe, and another smaller one near the head of Las Palmas side lobe.

The Hurd Peninsula ice cap is subjected to the maritime climate of the western Antarctic Peninsula (AP) region. The annual average temperature at JCI during the period 1994-2014 was $-1.2^{\circ} \mathrm{C}$, with average summer (DecemberJanuary-February) and winter (June-July-August) temperatures of 1.9 and $-4.7^{\circ} \mathrm{C}$, respectively (Bañón and Vasallo, 2016). Summer, winter, and annual mass balances have been measured using the glaciological method on the same network of stakes used for the glacier velocity measurements and then integrated to the entire glacier basins. The mean surface mass balances over the period 2002-2011 have not been significantly different from zero for either glacier: $0.05 \pm$ $0.30 \mathrm{~m}$ w.e. for Johnsons and $-0.15 \pm 0.44 \mathrm{~m}$ w.e. for Hurd. The ranges indicate the SDs, showing that the mass balances have a noticeable interannual variability. The estimated errors of the annual mass balances are lower (approximately $\pm 0.1 \mathrm{mw}$.e.). The slightly more negative balance for Hurd Glacier is due to its lower accumulation rates, attributed to snow redistribution by wind, together with higher ablation rates due to Hurd's hypsometry, which shows a much larger share of area at the lowermost altitudes $(<100 \mathrm{~m})$ as compared with Johnsons (Navarro et al., 2013). The average accumulation area ratios over the same period were $44 \pm 24 \%$ for Hurd Glacier and $61 \pm 21 \%$ for Johnsons Glacier (in mean and SD). Their equilibrium line altitudes (ELA) for the same period were $228 \pm 57$ and $187 \pm 37 \mathrm{~m}$ a.s.l., respectively (Navarro et al., 2013).

\section{Methods}

The glacier surface velocities were estimated based on repeated differential GNSS measurements in a network of stakes deployed by the authors on Johnsons and Hurd glaciers. The network consisted (at the end of 2013) of 22 stakes for Johnsons and 30 stakes for Hurd Glacier (Fig. 2). The location of the stakes was chosen to provide a wide spatial coverage of the glacier basins and their accumulation and ablation zones. Moreover, several sets of stakes were installed along predefined glacier flow lines in order to facilitate possible glacier dynamics modelling studies. Ease of access for stake measurements was also taken into consideration. Over the 14-year time period, some of the stakes have been lost (e.g. by iceberg calving at Johnsons Glacier front, because they have fallen due to intensive melting, or because they have been buried by heavy snowfalls), and new ones have been added. Because of this, there are differences in the set of stakes shown in the various figures in this paper, as they correspond to different snapshots in time. Also, the set of stakes included in the PANGAEA database (see Sect. 4) is larger than that in any of the figures because it includes all of the stakes that have existed at any time within the complete measurement period.

The stakes were surveyed two to four times per summer campaign during the period 2000-2013. Measurements are restricted to the summer season because Juan Carlos I Station operates only during the austral summer. At least one measurement at the beginning and another at the end of each summer season have been performed. In this way, we are able to compute not only annual-averaged velocities but also summer velocities and "extended winter" (all year excluding the summer) velocities. In some cases additional measurements during the summer provide temporal velocity variations during summer. The GNSS measurements were carried out using a Trimble 5700 system, with data controller TSC2. The measurements were performed either in real-time kinematics (RTKs) or in fast-static (post-processed) mode; for the former, an occupation time of $10 \mathrm{~s}$ was set, and for the latter it was 3-5 min depending on the number of satellites available. In general, RTK mode was used, but in some cases a radio link to the base station was not available and fast-static mode was employed. The GNSS base station was located at Juan Carlos I Station (Fig. 1) at a distance of 2$4 \mathrm{~km}$ from each stake measurement point. The base station Juan Carlos I is a permanent GNSS station with coordinates determined with an accuracy better than $0.007 \mathrm{~m}$ in horizontal and $0.012 \mathrm{~m}$ in vertical directions (Ramírez-Rodríguez, 2007). The estimated horizontal accuracy for the stake positions lies between 0.07 and $0.60 \mathrm{~m}$. The main contributor to this uncertainty is not the GNSS measurement error (which has average values of 0.07 and $0.10 \mathrm{~m}$ for horizontal and vertical positioning, respectively) but the estimated uncertainties in the correction for tilt of the stakes. The correction of the stake positions for tilt requires us to measure the tilt angle and the azimuth of the tilt. Throughout the 14-year measurement period, two different ways to correct for tilt were employed. One of them consisted in measuring the tilt using a clinometer and the azimuth using a compass and then making the corresponding geometric corrections. However, these measurements are especially difficult and can imply large uncertainties in the case of large tilts of stakes buried under snow. Moreover, the azimuth reading has to be corrected by magnetic declination and by a grid convergence factor, both of which involve uncertainties. A second method used was 


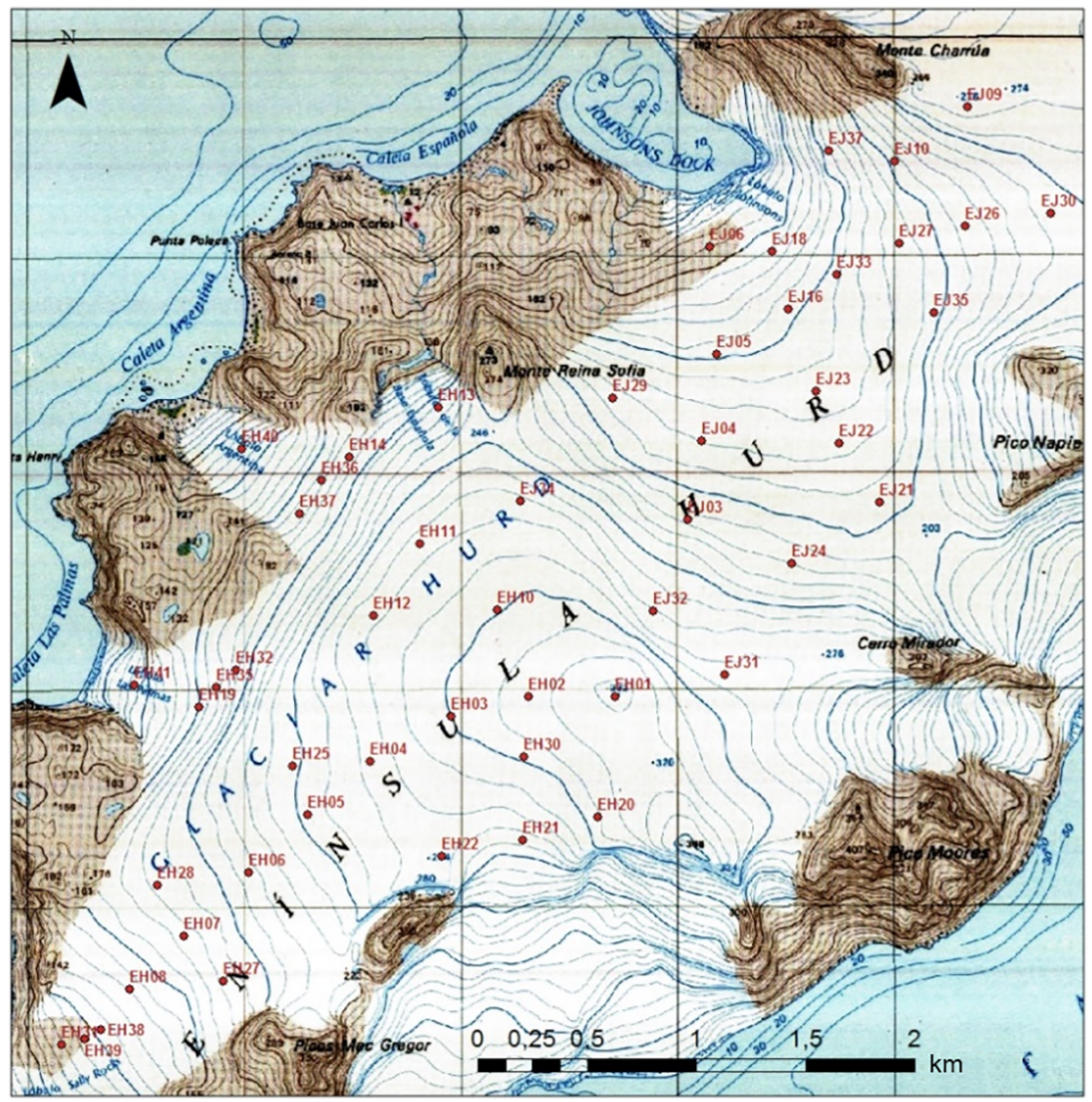

Figure 2. Network of stakes on Hurd and Johnsons glaciers at the end of the 2012-2013 Antarctic summer campaign. (Base map: SGE, 1991.)

to measure two different points on the stake and to compute tilt and azimuth from their coordinates. However, for stakes tilted and deeply buried under snow these two points are usually close to each other, which implies larger errors. The estimated coordinates of the stakes were projected into the UTM system for Zone 20S.

From the collected positions of the stakes at discrete times, the stake positions at any time can be estimated by applying the procedure described below. We will just focus on horizontal velocities, since the vertical component of the velocity is very small and prone to errors such as those of the tilt of the stake. From the known position $\left(x_{t_{i}}, y_{t_{i}}\right)$ of a stake at a given time $t_{i}$ (expressed in days since 1 January 1999 at 00:00), with the subscript $i$ indicating the sequential number of the observation (from $i=1$ to $i=n$ ), we define the planimetric position of a stake over time (i.e. its trajectory) by the discrete functions

$X\left(t_{i}\right)=X\left(x_{t_{1}}, x_{t_{2}}, \ldots, x_{t_{n}}\right)$,
$Y\left(t_{i}\right)=Y\left(y_{t_{1}}, y_{t_{2}}, \ldots, y_{t_{n}}\right)$

We approximate the stake positions with a second-degree polynomial, which is equivalent to assuming that the stake moves with constant acceleration:

$X_{a}\left(t_{i}\right)=a_{x} t_{i}^{2}+b_{x} t_{i}+c_{x}$,

$Y_{a}\left(t_{i}\right)=a_{y} t_{i}^{2}+b_{y} t_{i}+c_{y}$.

The unknown coefficients are determined by the least-square fitting method, minimizing the residual vectors

$$
\begin{aligned}
& \boldsymbol{R}_{x}=\left[\begin{array}{ccc}
t_{1}^{2} & t_{1} & 1 \\
t_{2}^{2} & t_{2} & 1 \\
\ldots & \ldots & \ldots \\
t_{n}^{2} & t_{n} & 1
\end{array}\right]\left[\begin{array}{l}
a_{x} \\
b_{x} \\
c_{x}
\end{array}\right]-\left[\begin{array}{c}
X\left(t_{1}\right) \\
X\left(t_{2}\right) \\
\ldots \\
X\left(t_{n}\right)
\end{array}\right] \\
& =\boldsymbol{A} \boldsymbol{C}_{x}-\boldsymbol{X}, \\
& \boldsymbol{R}_{y}=\left[\begin{array}{ccc}
t_{1}^{2} & t_{1} & 1 \\
t_{2}^{2} & t_{2} & 1 \\
\ldots & \ldots & \ldots \\
t_{n}^{2} & t_{n} & 1
\end{array}\right]\left[\begin{array}{c}
a_{y} \\
b_{y} \\
c_{y}
\end{array}\right]-\left[\begin{array}{c}
Y\left(t_{1}\right) \\
Y\left(t_{2}\right) \\
\ldots \\
Y\left(t_{n}\right)
\end{array}\right] \\
& =\boldsymbol{A} \boldsymbol{C}_{y}-\boldsymbol{Y} .
\end{aligned}
$$

Minimization of $\boldsymbol{R}_{x}\left(\boldsymbol{R}_{y}\right)$ yields the coefficients for $X_{a}\left(Y_{a}\right)$ describing the stake positions over time. From the time derivatives of the positions, the horizontal velocity of a stake 
will be given by the expressions

$$
\begin{aligned}
& \boldsymbol{v}=v_{x} \boldsymbol{i}+v_{y} \boldsymbol{j}, \\
& v_{x}=X_{a}{ }^{\prime}\left(t_{i}\right)=2 a_{x} t_{i}+b_{x}, \\
& v_{y}=Y_{a}{ }^{\prime}\left(t_{i}\right)=2 a_{y} t_{i}+b_{y}, \\
& \|\boldsymbol{v}\|=\sqrt{v_{x}^{2}+v_{y}^{2}} .
\end{aligned}
$$

To obtain the error estimates $e_{x}$ and $e_{y}$ of the adjusted functions $X_{a}\left(t_{i}\right)$ and $Y_{a}\left(t_{i}\right)$ (from which we calculate the error in horizontal positioning as $e_{x y}=\sqrt{e_{x}^{2}+e_{y}^{2}}$, we follow the parametric adjustment procedure (Ghilani, 2010), which has to be applied separately for $X$ and $Y$ (for brevity, we just describe it below for $X$ ). For a least square approximation, assuming observations of equal weight, these equations are

$\boldsymbol{C}_{x}=\left[\boldsymbol{A}^{\mathrm{T}} \boldsymbol{A}\right]^{-1}\left[\boldsymbol{A}^{\mathrm{T}} \boldsymbol{X}\right]$,

$\boldsymbol{R}_{x}=\boldsymbol{A} \boldsymbol{C}_{x}-\boldsymbol{X}$

$\widetilde{\boldsymbol{X}}=\boldsymbol{X}+\boldsymbol{R}_{x}, s$

$e_{x}=\sqrt{\frac{\boldsymbol{R}_{x}^{\mathrm{T}} \boldsymbol{R}_{x}}{r}}$

where $\boldsymbol{X}$ is the vector of observations, $\widetilde{\boldsymbol{X}}$ is the vector of estimates, $\boldsymbol{A}$ is the matrix of coefficients, $\boldsymbol{R}_{x}$ is the vector of residuals, $\boldsymbol{C}_{x}$ is the vector of unknowns (the coefficients in the polynomial adjustment), $e_{x}^{2}$ is the reference variance, and $r$ is the number of degrees of freedom $(r=n-3$, with $n$ the number of observations).

The above equations are solved for each stake trajectory. $\boldsymbol{C}_{x}$ is solved first to determine the coefficients of the seconddegree polynomial adjustment. Then, the adjusted values $\boldsymbol{A} \boldsymbol{C}_{x}$ are calculated and the residuals $\boldsymbol{R}_{x}$ computed, and finally the error in position $e_{x}$ is calculated. The process is repeated for the corresponding equations in the $y$ direction.

We note that the above error estimates do not represent actual errors in the data points but the SDs of the data point positions with respect to their corresponding values (for the same time $t$ ) in the polynomial approximation defined by Eq. (2).

The velocity error for a given stake between two particular positions $x_{i}=\left(x_{i}, y_{i}\right), x_{i+1}=\left(x_{i+1} y_{i+1}\right)$, with positioning errors $e_{x_{i}}, e_{x_{i+1}}$, respectively, separated by a time interval $\Delta t=t_{i+1}-t_{i}$ (i.e. the error in $\boldsymbol{v}_{i}=\frac{x_{i+1}-x_{i}}{\Delta t}$ ) is given by

$e_{v_{i}}=\frac{1}{\Delta t} \sqrt{e_{x_{i}}^{2}+e_{x_{i+1}}^{2}}$.

The error estimate resulting from the polynomial approximation is given by the root-mean-square deviation of observed and approximated values:

$$
\begin{aligned}
& e_{v_{x}}=\sqrt{\frac{1}{N} \sum_{i=1}^{N}\left(v_{x_{i}}^{\mathrm{obs}}-v_{x_{i}}^{\mathrm{pol}}\right)^{2},} \\
& e_{v_{y}}=\sqrt{\frac{1}{N} \sum_{i=1}^{N}\left(v_{y_{i}}^{\mathrm{obs}}-v_{y_{i}}^{\mathrm{pol}}\right)^{2},} \\
& \left\|e_{v}\right\|=\sqrt{e_{v_{x}}^{2}+e_{v_{y}}^{2}},
\end{aligned}
$$

where $\boldsymbol{v}_{i}^{\mathrm{obs}}=\frac{x_{i+1}-x_{i}}{\Delta t}=\left(v_{x_{i}}^{\mathrm{obs}} v_{y_{i}}^{\mathrm{obs}}\right)$ is the average observed velocities calculated for each time interval and $v_{i}^{\mathrm{pol}}=$ $\left(v_{x_{i}}^{\mathrm{pol}} v_{y_{i}}^{\mathrm{pol}}\right)$ is the corresponding velocities calculated using Eq. (4) for time $\frac{t_{i}+t_{i+1}}{2}$, and $N$ represents the number of velocity intervals $(N=n-1$, with $n$ the number of stake position observations). Note that the value given by Eq. (7) is a single value representing the average error for each polynomial approximation (i.e. a single error value for each stake), while the errors given by Eq. (6) are interval velocity errors between two consecutive positions of a given stake. The errors for the interval velocities are naturally much higher because they do not contain the smoothing from the polynomial approximation.

\section{Results}

The procedure described above was applied to every stake that has existed for any subperiod (perhaps the entire period) within the complete measurement period 2000-2013. The data are available at the PANGAEA database (http://doi. pangaea.de/10.1594/PANGAEA.846791) and are further described in Appendix A.

The results for the coefficients of the polynomial adjustments for the stake positions and the estimated horizontal positioning misfits for each stake are given in Table B1 of Appendix B. To illustrate the order of magnitude of the velocities and their associated errors, as well as their spatial variations, we have included in Table 1 the calculated values for 13 February 2013.

As an example, the detailed results for a particular stake, EJ14, are shown in Table 2 and Fig. 3. The latter shows the position changes of the stake over time.

In Figs. 4 and 5 we show the horizontal velocities (absolute values and directions) for all stakes of Hurd and Johnsons glaciers, respectively, for a given date (13 February 2013), calculated using the corresponding polynomial adjustments. We also show the corresponding contour lines of the absolute value of the velocities for the same date, calculated from the spatial interpolation of the velocity vector field. Maximum velocities on Hurd Glacier are only of a few metres per year, and approach $10 \mathrm{myr}^{-1}$ at the head of the unnamed glacier draining towards the south. Maximum velocities on Johnsons Glacier are much larger, up to several tens of metres per year, and reached $65 \mathrm{~m} \mathrm{yr}^{-1}$ near the calving front. The location of 
Table 1. Horizontal velocities for Hurd and Johnsons glacier stakes on 13 February 2013, calculated using the first-degree polynomial for velocity derived from the second-degree polynomial adjustment for stake positions. From left to right: stake name, $X$ and $Y$ components of horizontal velocity $\left(v_{x}, v_{y}\right)$, absolute value of horizontal velocity $(\|\boldsymbol{v}\|)$, azimuth of horizontal velocity vector $(\theta)$, and error estimate for the horizontal velocity $\left(\left\|e_{v}\right\|\right)$, calculated using the polynomial fit.

\begin{tabular}{lrrrrr}
\hline Stake & $v_{x}\left(\mathrm{myr}^{-1}\right)$ & $v_{y}\left(\mathrm{~m} \mathrm{yr}^{-1}\right)$ & $\|\boldsymbol{v}\|\left(\mathrm{m} \mathrm{yr}^{-1}\right)$ & $\theta\left(^{\circ}\right)$ & $\left\|e_{\boldsymbol{v}}\right\|\left(\mathrm{m} \mathrm{yr}^{-1}\right)$ \\
\hline EH01 & -0.4 & -0.6 & 0.7 & 210 & \pm 0.4 \\
EH02 & -0.8 & 0.0 & 0.8 & 269 & \pm 0.5 \\
EH03 & -0.9 & -0.3 & 1.0 & 249 & \pm 0.4 \\
EH04 & -1.7 & -0.4 & 1.8 & 255 & \pm 0.3 \\
EH05 & -1.9 & -0.8 & 2.1 & 247 & \pm 0.2 \\
EH06 & -2.9 & -1.1 & 3.1 & 250 & \pm 0.3 \\
EH07 & -2.8 & -1.8 & 3.4 & 238 & \pm 0.7 \\
EH08 & -2.3 & -1.9 & 3.0 & 230 & \pm 0.3 \\
EH10 & -0.9 & 1.0 & 1.3 & 319 & \pm 0.2 \\
EH11 & -1.2 & 1.4 & 1.9 & 319 & \pm 0.2 \\
EH12 & -1.0 & 0.5 & 1.2 & 297 & \pm 1.6 \\
EH13 & -1.1 & 1.5 & 1.9 & 324 & \pm 0.2 \\
EH14 & -0.9 & 0.3 & 1.0 & 290 & \pm 0.8 \\
EH19 & -1.5 & 0.5 & 1.6 & 288 & \pm 0.3 \\
EH20 & -1.5 & -0.6 & 1.6 & 249 & \pm 0.6 \\
EH21 & -2.3 & -9.8 & 10.0 & 193 & \pm 0.6 \\
EH22 & -0.6 & -0.8 & 1.0 & 216 & \pm 0.7 \\
EH25 & -2.1 & -0.1 & 2.1 & 268 & \pm 0.2 \\
EH27 & -2.5 & -1.3 & 2.8 & 242 & \pm 0.2 \\
EH28 & -1.3 & -0.6 & 1.4 & 246 & \pm 0.4 \\
EH30 & -1.9 & -2.8 & 3.4 & 213 & \pm 4.9 \\
EH31 & -1.1 & -0.6 & 1.3 & 240 & \pm 0.9 \\
EH32 & -0.5 & 0.3 & 0.6 & 300 & \pm 1.0 \\
EH35 & -2.2 & 0.8 & 2.3 & 290 & \pm 0.5 \\
EH36 & -1.7 & 1.8 & 2.5 & 318 & \pm 1.1 \\
EH37 & -2.3 & 1.6 & 2.8 & 305 & \pm 1.4 \\
EH38 & -2.2 & -1.9 & 2.9 & 229 & \pm 0.7 \\
EH39 & -2.2 & -1.6 & 2.7 & 235 & \pm 0.4 \\
EH40 & -2.2 & 2.1 & 3.0 & 313 & \pm 0.3 \\
EH41 & -0.7 & -0.7 & 1.0 & 223 & \pm 1.7 \\
EJ03 & 2.4 & 6.6 & 7.0 & 20 & \pm 0.7 \\
EJ04 & 0.9 & 7.3 & 7.3 & 7 & \pm 1.0 \\
EJ05 & 0.6 & 10.9 & 11.0 & 3 & \pm 1.9 \\
EJ06 & -5.7 & 23.5 & 24.2 & 346 & \pm 0.5 \\
EJ09 & 0.0 & 0.0 & 0.0 & 135 & \pm 0.3 \\
EJ10 & -4.1 & -2.0 & 4.6 & 245 & \pm 1.1 \\
EJ16 & -7.4 & 14.0 & 15.8 & 332 & \pm 2.3 \\
EJ18 & -22.6 & 29.3 & 37.0 & 322 & \pm 0.2 \\
EJ21 & -0.6 & 1.0 & 1.2 & 328 & \pm 0.4 \\
EJ22 & -1.4 & 3.6 & 3.8 & 339 & \pm 0.6 \\
EJ23 & -1.8 & 6.5 & 6.8 & 344 & \pm 0.3 \\
EJ24 & 1.0 & 5.2 & 5.3 & 11 & \pm 0.6 \\
EJ26 & -7.2 & -2.7 & 7.7 & 250 & \pm 1.2 \\
EJ27 & -13.5 & -2.4 & 13.7 & 260 & \pm 0.3 \\
EJ29 & 3.5 & 3.2 & 4.8 & 47 & \pm 0.1 \\
EJ30 & -1.9 & -1.6 & 2.4 & 230 & \pm 0.2 \\
EJ31 & 1.4 & 2.7 & 3.1 & 26 & \pm 0.4 \\
EJ32 & 2.0 & 2.2 & 3.0 & 41 & \pm 1.8 \\
EJ33 & -14.2 & 5.6 & 15.3 & 291 & \pm 0.3 \\
EJ34 & 0.2 & 1.6 & 1.6 & 7 & \pm 7.1 \\
EJ35 & -6.3 & -0.4 & 6.3 & 266 & \pm 0.4 \\
\hline & & & & &
\end{tabular}



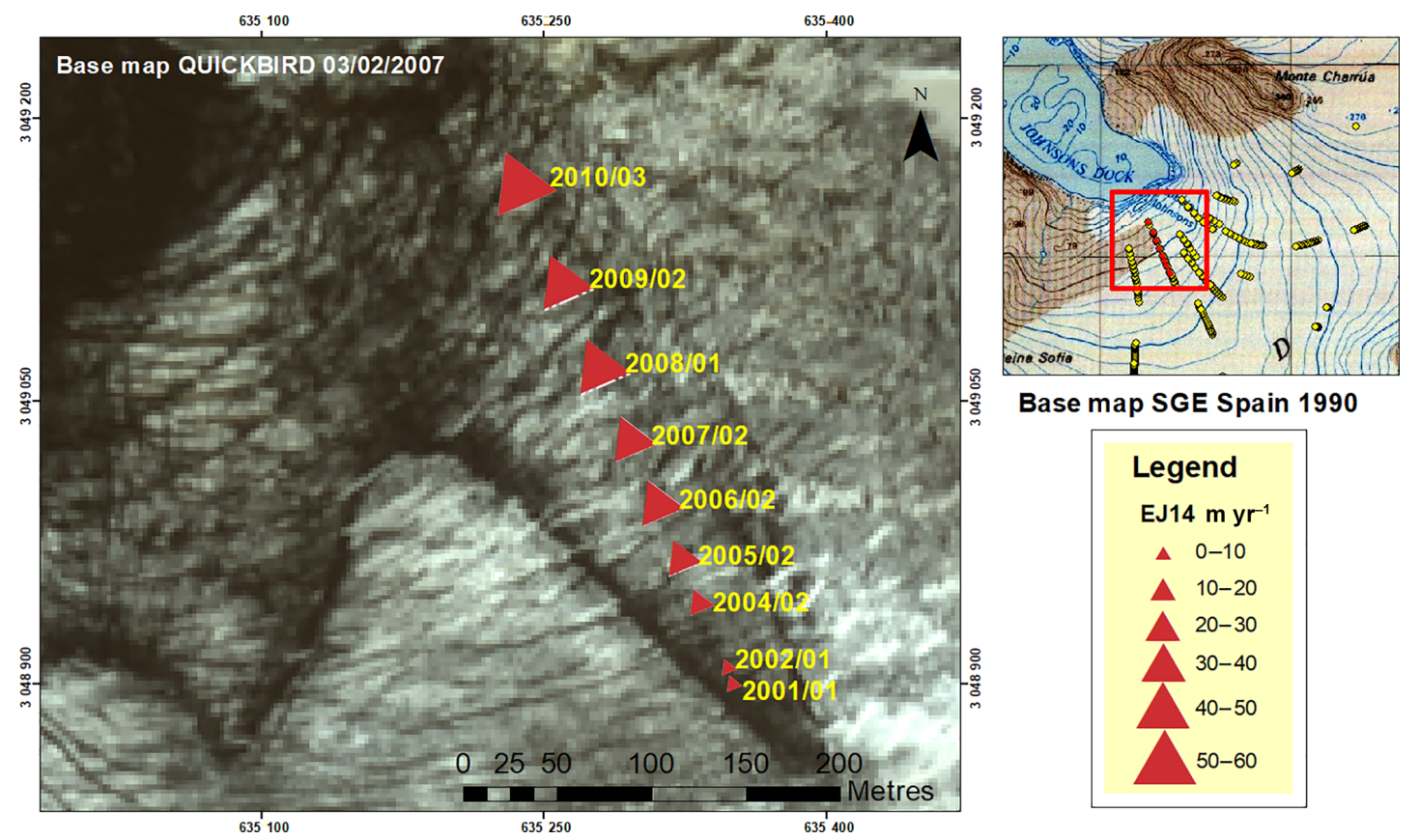

Base map SGE Spain 1990

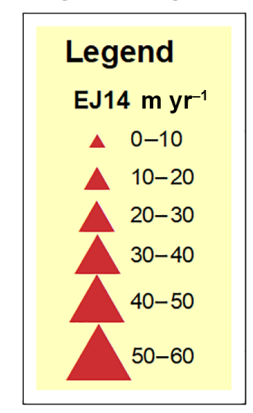

Figure 3. Map showing the time evolution of stake EJ14. Horizontal velocities and times for various positions are shown. The stake fell into a crevasse during 2010-2011, so it does not appear in Fig. 2. The inset shows the location of the main image (in the inset, EJ14 positions are shown in green). In this, and the following figures, UTM coordinates (sheet 20S) are indicated. The background satellite image is a photo from the QUICKBIRD system program (2007).

Table 2. Example of results for the adjustment by least squares of the position and the velocity of a stake (EJ14, near the calving front of Johnsons Glacier; see Fig. 3), together with the deviations from the polynomial approximation for the position, as well as the maximum horizontal velocity and its direction.

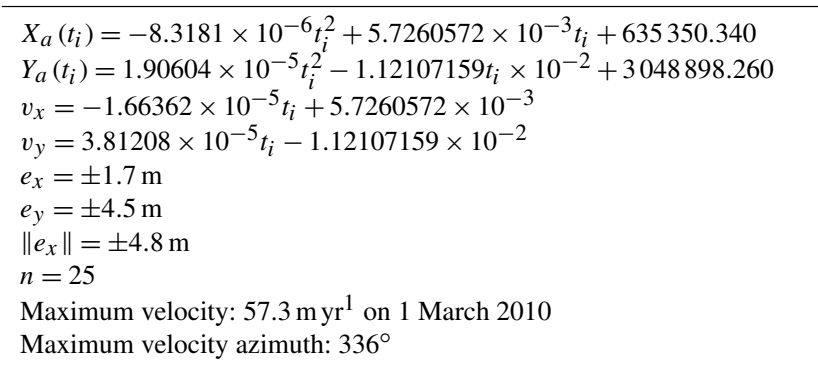

the main ice divides is apparent in the contour plots (zero velocity bands).

\section{Data availability}

Continuous velocity model for Johnsons and Hurd glaciers from 1999 to 2013, with a link to model results in shapefile format, is available at http://doi.pangaea.de/10.1594/ PANGAEA.846791 (Rodríguez Cielos and Navarro Valero, 2015).

\section{Discussion and summarizing conclusions}

From the analysis of Figs. 4-5, we see that Johnsons and Hurd glaciers show two markedly different dynamical regimes. Since Johnsons is a tidewater glacier, it shows a pattern of velocities increasing from the ice divides (where horizontal velocities normal to the divide are zero by definition) towards its calving front, where yearly-averaged velocities up to $65 \mathrm{~m} \mathrm{yr}^{-1}$ have been observed (Fig. 5). Hurd, on the other hand, is a land-terminating glacier, with much slower velocities (typically just a few metres per year), in which the largest velocities are reached in its middle to lower part (between stakes EH06 and EH08; see Fig. 4), where basal sliding likely occurs. The velocity field close to the landterminating snouts shows a decreasing pattern (this is particularly noticeable in the snouts of Sally Rocks and Las Palmas lobes). Velocities are also high in the high-slope zones such as the Argentina lobe and the upper part of the Las Palmas lobe. Note that the high-velocity zone shown to the southeast of Hurd glacier, around stake EH21 (Fig. 4) does not really correspond to Hurd Glacier but to an unnamed glacier flowing southwards, towards False Bay, which has extremely steep slopes and is in fact a heavily crevassed icefall.

The decreasing velocities as we approach the landterminating snouts have been attributed to the fact that the surficial cold ice layer reaches the bed in these zones, so the glacier is frozen to its bed and glacier movement is produced by internal deformation alone (no basal sliding). This is sup- 


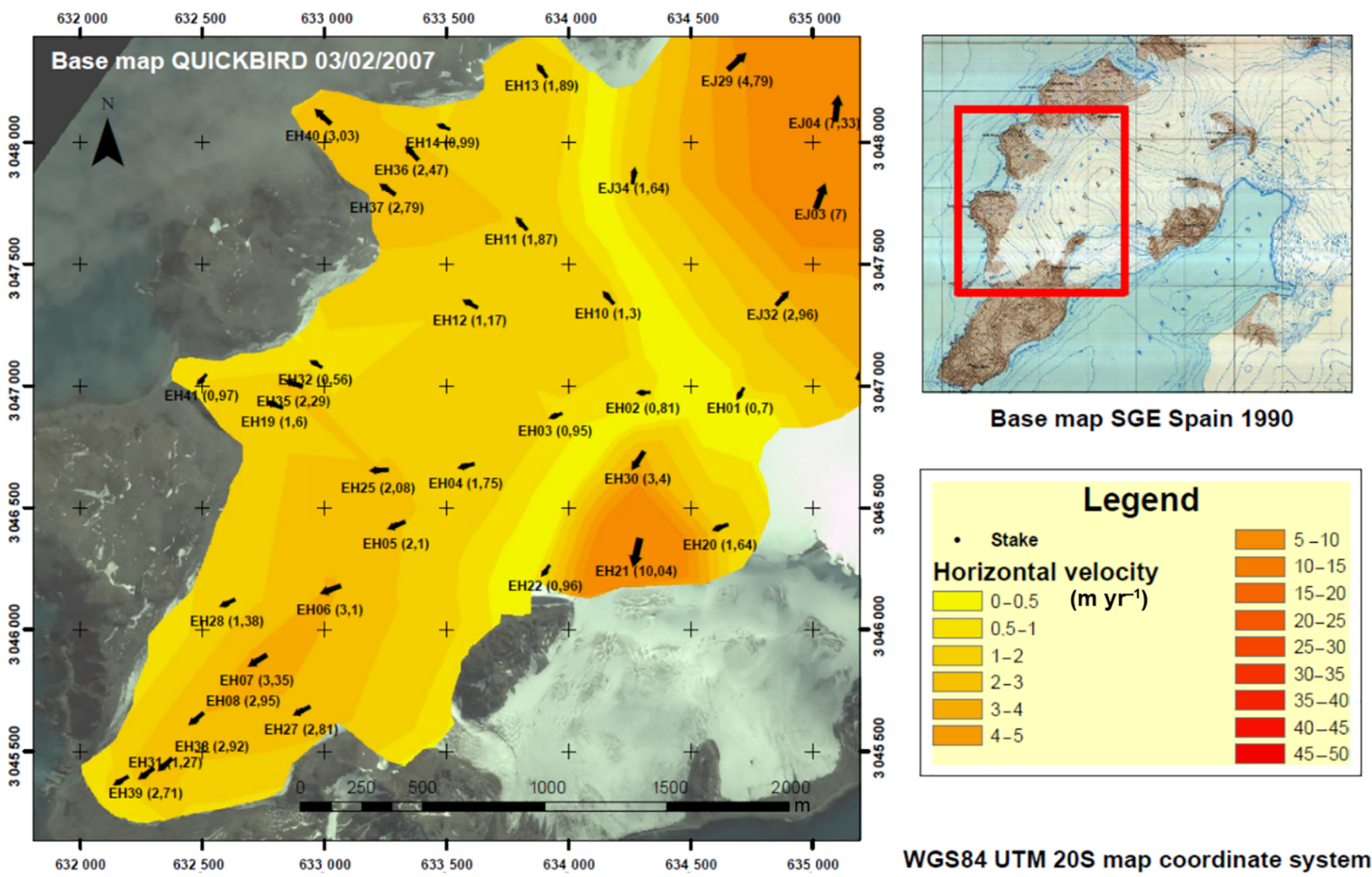

Figure 4. Map of contour lines of the absolute values of the horizontal velocity for Hurd Glacier, obtained from the spatial interpolation of the corresponding vector velocity field, calculated for 13 February 2013. The magnitude of velocity is denoted in brackets, arrows indicate direction. The yellow near-zero velocity band indicates the approximate location of the ice divides.

ported by both geomorphological observations, in particular the presence of compressional structures such as thrust faults close to the glacier termini (Molina et al., 2007; Molina, 2014) and to ground-penetrating radar studies that show that the cold ice layer reaches the bedrock in these zones (Navarro et al., 2009; Molina, 2014).

From the analysis of the polynomial interpolation of observed positions we see that a second-degree polynomial function (representing a uniformly accelerated motion) is sufficient to provide a fair adjustment to the observed position changes. The largest positioning error (misfit of the polynomial approximation), of $4.8 \mathrm{~m}$, is found for stake EJ14, which had an estimated horizontal velocity of ca. $57 \mathrm{~m} \mathrm{yr}^{-1}$ on 1 March 2010. Of course, one of the major drawbacks of the polynomial interpolation of the observed positions is that it does not allow us to represent seasonal variations in glacier velocities, which are known to occur for the glaciers in this region (e.g. Osmanoğlu et al., 2014). In fact, we tried to add a sinusoidal function to the polynomial fit, and the results did not improve the fit to the observations at all. This result was anticipated because the positioning measurements are mostly done only at the beginning and the end of each summer season and thus do not allow us to resolve yearly cycles. But the polynomial interpolation of all available positions for a given stake is just an example of what can be done with the available data. Calculations could be done for estimating, e.g., summer-averaged velocities or winter-averaged velocities (for the "extended winter", i.e. all of the year except for the summer season). However, this is still insufficient to study velocity variations on scales shorter than the seasonal one. For this reason, perhaps the highest interest of the dataset presented is its use for tuning the free parameters of numerical models of glacier dynamics (Martín et al., 2004; Otero et al., 2010), since these models represent averaged velocities on time-step scales, which are often of the order of weeks (especially for steady-state models such as those cited, in which a limited time evolution is applied to get the model to reach a steady-state configuration). But even for transient models, weekly time steps are usual (e.g. Otero et al., 2017). The available dataset is also useful for the validation of remotely sensed SAR velocities, with typical repeat cycles from a few days to several tens of days (up to 45 days for ALOS PALSAR).

Another shortcoming of the dataset presented is that it does not allow for an easy analysis of dynamical responses to climate changes (such as those regionally observed by Oliva 


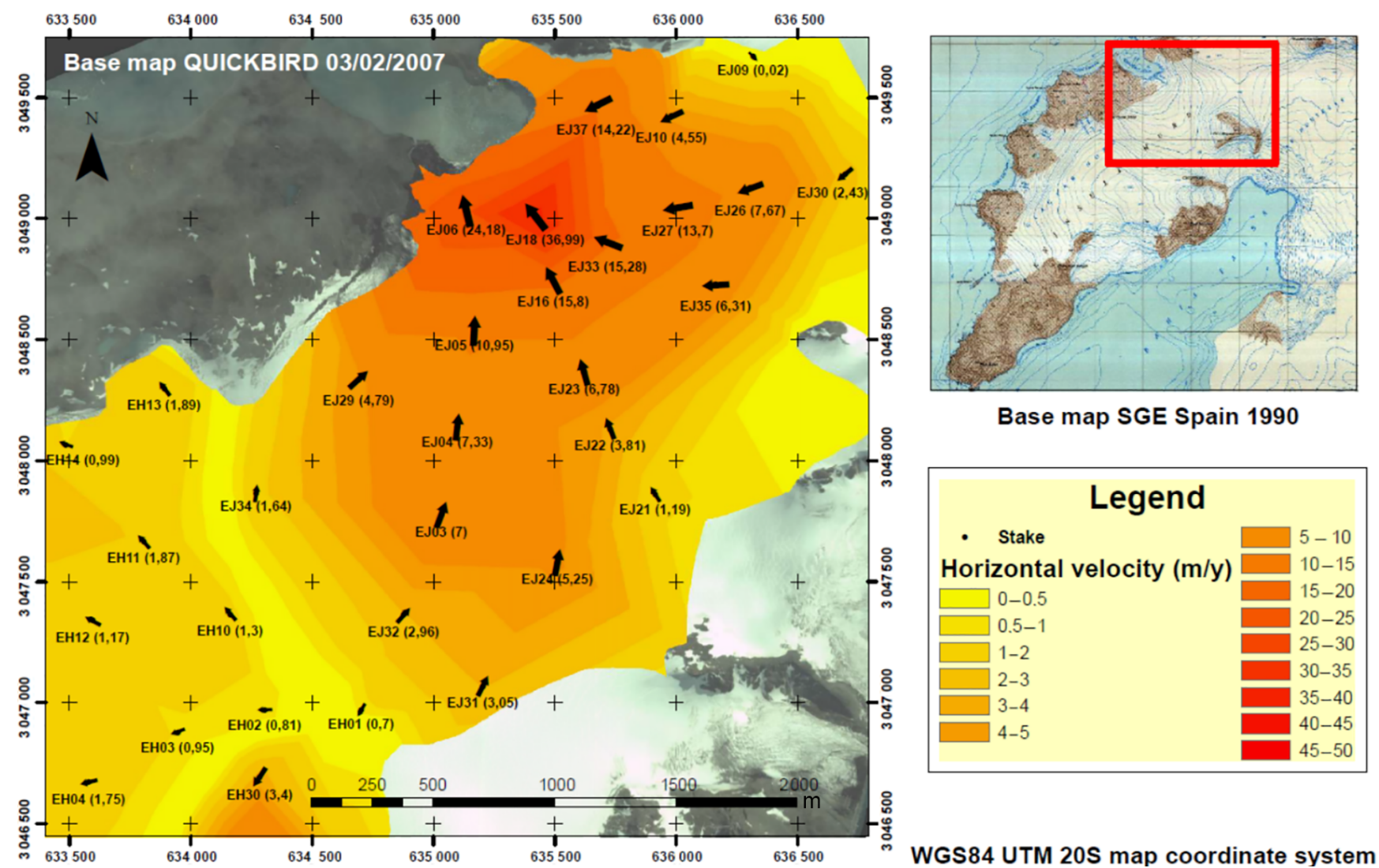

Figure 5. The magnitude of horizontal velocity for Johnsons Glacier, obtained from the spatial interpolation of the corresponding vector velocity field, calculated for 13 February 2013 using the first-degree polynomial derived from the second-degree polynomial adjustment of the stake positions. The numerical values for the absolute value of velocity at each stake (in brackets) and the vector velocity directions (arrows) are also represented. The yellow near-zero velocity band indicates the approximate location of the ice divides (except for the zone to the east, between UTM northing 3048000 and 3048500 , which corresponds to a zone of thin ice frozen to the bed on the upper part of a nunatak).

et al., 2016) because what is available is a Lagrangian velocity field (velocities measured at stakes that change their position with time), while what is needed for studying glacier velocity variations in response to climate changes is an Eulerian velocity field (velocities measured at a fixed location in space).

From the above discussion, a desirable complement to the available in situ velocity dataset presented in this paper would be a continuous record of ice velocities at selected stakes.
Summarizing, the dataset presented is a useful source of input data for numerical models of glacier dynamics and for the calibration-validation of remotely sensed velocity data. It fills an observational data gap in the region peripheral to the Antarctic Peninsula, and it is thus expected that these data will contribute to the understanding of the dynamics of the ice masses in this region and their response to environmental changes. 


\section{Appendix A}

The shape file CNDA-ESP_SIMRAD_VELOCITY.shp available in the PANGAEA database (http://doi.pangaea. de/10.1594/PANGAEA.846791), and its corresponding versions in Excel (.xlsx) and ASCII (.txt) formats, contain the position data for all stakes of Johnsons and Hurd glaciers for the period from 2000 to 2013. Below, we describe the contents of each individual field in the shape file, as described in file "fields_explanation.txt". We remind the reader that the set of stakes included in the data files is larger than that shown in the various figures in this paper, as it includes all stakes that have existed for any period within the entire measurement period, while the figures give snapshots in time. The PANGAEA data files also include a table (file "stake_dates.txt") indicating the dates of the start and the end of the measurement period for each stake.

- Field "t38_stake": the name of the stake under consideration (see stakes in Fig. 2).

- Field " $\mathrm{t} 38$ - $\mathrm{t} 0$ ": the zero time of the time variable; we set it as 1 January 1999 at 00:00 GMT.

- Field "t38_fecha": the date and time of the measurement, in "YYYYMMDDHHMMSS" format.

- Field "t38_inct": the period of time in days from "t38_t0" to "t38_fecha" ( $t_{n}$ in the above equations).

- Field "t38_x": $X$ coordinate in metres (UTM 20S) for the stake (considered in an ideal vertical position, after correction for tilt, if applicable) ( $x_{t_{n}}$ in Eq. 1).

- Field "t38_y": $Y$ coordinate in metres (UTM 20S) for the stake (considered in an ideal vertical position, after correction for tilt, if applicable) ( $y_{t_{n}}$ in Eq. 1).

- Field "t38_x_ide": $X$ coordinate in metres (UTM 20S) for the position of the stake for the given time, calculated using the second-degree polynomial adjustment $\left(X_{a}\left(t_{n}\right)\right.$ in Eq. 2).

- Field "t38_y_ide": $Y$ coordinate in metres (UTM 20S) for the position of the stake for the given time, calculated using the second-degree polynomial adjustment $\left(Y_{a}\left(t_{n}\right)\right.$ in Eq. 2).

- Field "t38_vx": $X$ component for horizontal velocity of the stake for the given time, expressed in metres per year, calculated from the second-degree polynomial adjustment ( $v_{x}$ in Eq. 4).

- Field "t38_vy": $Y$ component for horizontal velocity of the stake for the given time, expressed in metres per year, calculated from the second-degree polynomial adjustment ( $v_{y}$ in Eq. 4).
- Field "t38_vxy": absolute value of horizontal velocity of the stake for the given time, expressed in metres per year, calculated from the $X$ and $Y$ components of the velocity obtained from the second-degree polynomial adjustment ( $\|\boldsymbol{v}\|$ in Eq. 4).

- Field "t38_v_aci": azimuth for horizontal velocity of the stake, expressed in sexagesimal degrees, at the date of the measurement.

- Field "t38_err_x": root-mean-squared deviation for the $X$ position of the stake, expressed in metres $\left(e_{x}\right)$.

- Field "t38_err_y": root-mean-squared deviation for the $Y$ position of the stake, expressed in metres $\left(e_{y}\right)$.

- Field "t38_max_x": maximum error obtained for the $X$ position of the stake, expressed in metres.

- Field "t38_max_y": maximum error obtained for the $Y$ position of the stake, expressed in metres.

- Field "t38_ax": the estimation of the " $\mathrm{a}_{x}$ " coefficient in the second-degree polynomial adjustment of the position $X$ of the stake ( $a_{x}$ in Eq. 2 ).

- Field "t38_bx": the estimation of the " $\mathrm{b}_{x}$ " coefficient in the second-degree polynomial adjustment of the position $X$ of the stake ( $b_{x}$ in Eq. 2).

- Field "t38_cx": the estimation of the "c $c_{x}$ " coefficient in the second-degree polynomial adjustment of the position $X$ of the stake ( $c_{x}$ in Eq. 2).

- Field "t38_ay": the estimation of the " $\mathrm{a}_{y}$ " coefficient in the second-degree polynomial adjustment of the position $Y$ of the stake ( $a_{y}$ in Eq. 2).

- Field "t38_by": the estimation of the "by" coefficient in the second-degree polynomial adjustment of the position $Y$ of the stake ( $b_{y}$ in Eq. 2).

- Field "t38_cy": the estimation of the "c $y_{y}$ " coefficient in the second-degree polynomial adjustment of the position $Y$ of the stake ( $c_{y}$ in Eq. 2).

- Field "dias": days after t38_t0 for a simulation (in this example, 5817 days).

- Field "prevista_x": example of $X$ coordinate in metres (UTM 20S) for the stake (considered in an ideal vertical position, after correction for tilt) after 5817 days.

- Field "prevista_y": example of $Y$ coordinate in metres (UTM 20S) for the stake (considered in an ideal vertical position, after correction for tilt) after 5817 days.

- Field "movxy": planimetric movement in metres (UTM 20S) for the stake (considered in an ideal vertical position, after correction for tilt) after 5817 days. 
Appendix B

Table B1. Polynomial coefficients of the adjustment functions $X_{a}\left(t_{i}\right)$ and $Y_{a}\left(t_{i}\right)$, according to Eq. (2) for all the stakes of the glaciers under study. The units for the coefficients $a, b$, and $c$ are $\mathrm{m} \mathrm{yr}^{-2}, \mathrm{~m} \mathrm{yr}^{-1}$ and $\mathrm{m}$, respectively. The table also shows the estimated horizontal positioning errors $\left(\left\|e_{x}\right\|=\sqrt{e_{x}^{2}+e_{y}^{2}}\right.$, in metres) involved in the polynomial approximation of the position.

\begin{tabular}{|c|c|c|c|c|c|c|c|}
\hline Stake & $a_{x}$ & $b_{x}$ & $c_{x}$ & $a_{y}$ & $b_{y}$ & $c_{y}$ & $\left\|e_{x}\right\|(\mathrm{m})$ \\
\hline EH01 & -0.0000000210 & -0.0007499061 & 634706.536 & -0.0000001022 & -0.0006149926 & 3046974.077 & \pm 0.4 \\
\hline EH02 & -0.0000000260 & -0.0019490138 & 634314.937 & 0.0000000376 & -0.0004418479 & 3046972.371 & \pm 0.3 \\
\hline ЕH03 & 0.0000000017 & -0.0024338880 & 633957.992 & 0.0000000387 & -0.0013300512 & 3046883.749 & \pm 0.3 \\
\hline EH04 & 0.0000000208 & -0.0048559670 & 633602.733 & 0.0000000476 & -0.0016952866 & 3046680.172 & \pm 0.2 \\
\hline EH05 & 0.0000000827 & -0.0061748145 & 633322.971 & 0.0000000176 & -0.0023909505 & 3046440.393 & \pm 0.2 \\
\hline EH06 & 0.0000001329 & -0.0093454794 & 633066.469 & 0.0000001143 & -0.0041399749 & 3046183.071 & \pm 0.3 \\
\hline EH07 & 0.0000002467 & -0.0103102794 & 632769.911 & 0.0000001116 & -0.0060335306 & 3045901.732 & \pm 0.3 \\
\hline EH08 & 0.0000002202 & -0.0084839082 & 632511.087 & 0.0000002088 & -0.0073298445 & 3045661.923 & \pm 0.3 \\
\hline EH10 & -0.0000000115 & -0.0021984650 & 634172.352 & 0.0000000196 & 0.0024960084 & 3047352.461 & \pm 0.2 \\
\hline EH11 & -0.0000000060 & -0.0033251769 & 2.848 & -0.0000000136 & 0040018668 & 3047646.355 & \pm 0.2 \\
\hline EH12 & 0.0000000058 & -0.0029001077 & 633610.294 & 0.0000000058 & 0.0014133530 & & \\
\hline EH13 & 0.0000000989 & -0.0040996188 & 633908.319 & 0.0000000699 & 0.0034554549 & 3048276.555 & \pm 0.3 \\
\hline EH14 & 0.0000003949 & -0.0066196722 & 633507.694 & -0.0000000176 & 0.0011105547 & 3048060.055 & \pm 0.7 \\
\hline EH16 & & 919 & & -0.0 & 4677 & 8.378 & \pm 0.4 \\
\hline EH18 & 266 & & & & 1018 & & \pm 0.5 \\
\hline EH19 & 0.0000001954 & -0.0062025268 & 632821.167 & 0.0000000024 & 0.0013091532 & 3046916.708 & \pm 0.4 \\
\hline EH20 & -0.0000000041 & -0.0041607075 & 634641.903 & 0.0000000207 & -0.0018151514 & 3046428.116 & \pm 0.4 \\
\hline EH21 & 0.0000000702 & 64784 & 1.036 & -0.0000013781 & -0.012 & 3046415.468 & \pm 0.8 \\
\hline EH22 & 0.0000000418 & 778722 & 633913.716 & 0.0000000351 & -0.0024914249 & 3046250.139 & \pm 0.3 \\
\hline EH23 & 0.0000000850 & -0.0074476651 & 633 & -0.0000000048 & -0.004 & 6.767 & \pm 0.3 \\
\hline EH25 & 0.0000001059 & -0.0067918760 & 633252.533 & 0.0000000337 & -0.0005615131 & 3046656.096 & \pm 0.2 \\
\hline EH26 & 0.0000000665 & -0.0061374875 & 633283.461 & 0.0000000429 & -0.0008986263 & 3046923.597 & \pm 0.3 \\
\hline EH27 & & & & & 636 & & \pm 0.3 \\
\hline EH28 & 0000003036 & -0.0065784553 & 632626.203 & 0.0000002354 & -0.0039697127 & 0.387 & \pm 0.4 \\
\hline EH30 & -0.0000001863 & -0.0031881664 & 634304.297 & -0.0000004025 & -0.0036269810 & 3046722.181 & \pm 1.3 \\
\hline EH31 & 0.0000004603 & -0.0077532371 & 632191.166 & 0.0000002463 & -0.0042862662 & 3045393.753 & \pm 0.5 \\
\hline EH32 & 0000004228 & -0.0056874228 & 632981.252 & 0.0000000427 & 263696 & 3047088.876 & \pm 0.8 \\
\hline EH34 & 0.00000 & -0.02 & 6334 & -0.0000004808 & 0.0070931604 & 3047929.344 & \pm 0.3 \\
\hline EH35 & -0.0000001494 & -0.0043610240 & 632899.866 & 0.0000001839 & 0.0002225731 & 3047005.252 & \pm 0.3 \\
\hline EH36 & -0.0000000071 & -0.0044714224 & 633378.639 & -0.0000008964 & 0.0142598599 & 3047909.661 & \pm 1.4 \\
\hline EH37 & 0.0000001050 & -0.0073407541 & 633291.187 & -0.0000008597 & 0.0132842232 & 3047763.133 & \pm 0.8 \\
\hline EH38 & 0.0000000544 & -0.0065644463 & 632376.878 & -0.0000002724 & -0.0024698302 & 3045462.670 & \pm 0.3 \\
\hline EH39 & -0.0000000968 & -0.0050881561 & 632296.779 & -0.0000001033 & -0.0031726807 & 3045423.513 & \pm 0.2 \\
\hline EH40 & 0.0000001909 & -0.0080001652 & 633027.591 & -0.0000000767 & 0.0064788163 & 3048074.317 & \pm 0.1 \\
\hline EH41 & 0.0000016791 & -0.0191464499 & 632550.165 & -0.0000027307 & 0.0262539089 & 3046960.654 & \pm 0.6 \\
\hline EJ03r & -0.0000001531 & 0.0100735338 & 634980.227 & 0.0000004252 & 0.0182063987 & 3047658.850 & \pm 0.8 \\
\hline EJ04 & -0.0000003723 & 0.0061601161 & 635075.122 & -0.0000005812 & 0.0259414549 & 3048020.871 & \pm 1.2 \\
\hline EJ05 & 0.0000000492 & 0.0011547502 & 635161.004 & -0.0000003319 & 0.0333842531 & 3048375.872 & \pm 1.8 \\
\hline
\end{tabular}


Table B1. Continued.

\begin{tabular}{|c|c|c|c|c|c|c|c|}
\hline Stake & $a_{x}$ & $b_{x}$ & $c_{x}$ & $a_{y}$ & $b_{y}$ & $c_{y}$ & $\left\|e_{x}\right\|(\mathrm{m})$ \\
\hline EJ05r & -0.0000004208 & 0.0031517495 & 635155.477 & -0.0000019291 & 0.0363184602 & 3048344.319 & \pm 1.6 \\
\hline EJ06 & -0.0000011073 & -0.0042784868 & 635185.239 & 0.0000026943 & 0.0365926573 & 3048770.902 & \pm 3.1 \\
\hline EJ06r & 0.0000016211 & -0.0103198593 & 635192.433 & -0.0000178994 & 0.0932484671 & 3048692.082 & \pm 3.8 \\
\hline EJ09 & 0.0000000101 & -0.0000640752 & 636317.040 & 0.0000000306 & -0.0003560897 & 3049669.857 & \pm 0.2 \\
\hline EJ10 & -0.0000004307 & -0.0068225266 & 636026.014 & 0.0000000111 & -0.0054558209 & 3049450.521 & \pm 0.5 \\
\hline EJ11 & -0.0000056619 & -0.0199142185 & 635701.041 & 0.0000047076 & -0.0040812151 & 3049278.770 & \pm 1.1 \\
\hline EJ14 & -0.0000083181 & 0.0057260572 & 635350.340 & 0.0000190604 & -0.0112107159 & 3048898.259 & \pm 4.8 \\
\hline $\mathrm{EJ} 14 \mathrm{r}$ & 0.0000026146 & -0.0265096848 & 635395.318 & -0.0000095539 & 0.0757322689 & 3048785.930 & \pm 1.5 \\
\hline EJ15 & -0.0000115713 & -0.0150161625 & 635587.960 & 0.0000177466 & -0.0141862506 & 3049134.762 & \pm 4.5 \\
\hline EJ16 & -0.0000012393 & -0.0075342532 & 635564.261 & 0.0000014961 & 0.0227882933 & 3048586.798 & \pm 1.7 \\
\hline EJ16r & 0.0000001769 & -0.0118134174 & 635579.144 & 0.0000003110 & 0.0244004790 & 3048564.554 & \pm 1.5 \\
\hline EJ17 & -0.0000073534 & -0.0169745300 & 635820.867 & 0.0000070748 & -0.0119983441 & 3049058.204 & \pm 1.8 \\
\hline EJ17r & -0.0000017878 & -0.0295492517 & 635853.941 & 0.0000041007 & -0.0069866948 & 3049052.604 & \pm 1.1 \\
\hline EJ18 & -0.0000047503 & -0.0128379987 & 635611.869 & 0.0000072099 & 0.0059753470 & 3048787.784 & \pm 3.6 \\
\hline EJ18r & -0.0000020714 & -0.0198100707 & 635635.496 & 0.0000032380 & 0.0163894918 & 3048764.951 & \pm 2.1 \\
\hline EJ19r & -0.0000027156 & -0.0347723467 & 635509.766 & 0.0000039813 & 0.0474550026 & 3048954.395 & \pm 2.9 \\
\hline $\mathrm{EJ} 21$ & -0.0000000445 & -0.0012778820 & 635920.791 & 0.0000000648 & 0.0020946021 & 3047848.965 & \pm 0.1 \\
\hline $\mathrm{EJ} 22$ & 0.0000000237 & -0.0039724530 & 635745.947 & 0.0000000882 & 0.0088414448 & 3048083.628 & \pm 0.5 \\
\hline EJ23 & -0.0000000349 & -0.0046353861 & 635644.992 & 0.0000001090 & 0.0167557974 & 3048276.292 & \pm 0.9 \\
\hline EJ24 & -0.0000000521 & 0.0032607734 & 635493.978 & -0.0000001090 & 0.0152334223 & 3047502.873 & \pm 0.5 \\
\hline EJ26 & -0.0000009008 & -0.0103905425 & 636381.563 & -0.0000001309 & -0.0059871063 & 3049160.852 & \pm 0.7 \\
\hline EJ27 & -0.0000014544 & -0.0219763759 & 636156.950 & 0.0000004109 & -0.0107406457 & 3049090.100 & \pm 1.5 \\
\hline EJ28 & -0.0000031887 & 0.0011132529 & 636126.270 & 0.0000006713 & 0.0002700461 & 3048619.696 & \pm 1.3 \\
\hline EJ29 & -0.0000001806 & 0.0115365135 & 634635.956 & -0.0000000833 & 0.0097340264 & 3048288.181 & \pm 0.6 \\
\hline EJ30 & 0.0000002245 & -0.0074398001 & 636727.973 & 0.0000000834 & -0.0051238313 & 3049205.806 & \pm 0.1 \\
\hline EJ31 & -0.0000002608 & 0.0064071706 & 635177.240 & -0.0000004367 & 0.0119751394 & 3047018.091 & \pm 0.1 \\
\hline EJ32 & -0.0000002940 & 0.0083991531 & 634841.075 & -0.0000007905 & 0.0142317135 & 3047310.149 & \pm 0.3 \\
\hline EJ33 & 0.0000040527 & -0.0808182396 & 636025.782 & 0.0000004695 & 0.0104154497 & 3048835.009 & \pm 0.7 \\
\hline EJ34 & -0.0000001959 & 0.0026058368 & 634258.842 & -0.0000003753 & 0.0083361641 & 3047831.927 & \pm 0.1 \\
\hline EJ35 & -0.0000030794 & 0.0145204365 & 636169.067 & -0.0000019491 & 0.0189886987 & 3048680.544 & \pm 1.5 \\
\hline EJ36 & 0.0000098129 & -0.1574078351 & 636082.069 & -0.0000007515 & 0.0481336713 & 3048977.865 & \pm 1.0 \\
\hline EJ37 & -0.0000076218 & 0.0437382981 & 635654.292 & 0.0000010401 & -0.0281496644 & 3049584.987 & \pm 2.8 \\
\hline
\end{tabular}


Competing interests. The authors declare that they have no conflict of interest.

Acknowledgements. This work was supported by grant CTM2014-56473-R from the Spanish National Plan of R\&D. The suggestions by Christof Völksen and an anonymous reviewer, as well as the topical editor, Reinhard Drews, greatly contributed to improve the manuscript.

Edited by: Reinhard Drews

Reviewed by: Christof Völksen and one anonymous referee

\section{References}

Arthern, R. J. and Gudmundsson, G. H.: Initialization of ice-sheet forecasts viewed as an inverse Robin problem, J. Glaciol., 56, 527-533, 2011.

Bañón, M. and Vasallo, F.: AEMET en la Antártida, Climatología y meteorología sinóptica en las estaciones meteorológicas españolas en la Antártida, AEMET, Madrid., 152 pp., 2016.

Blindow, N., Suckro, S., Rückamp, M., Braun, M., Schindler, M., Breuer, B., Saurer, H., Simões, J. C., and Lange, M.: Geometry and status of the King George Island ice cap (South Shetland Islands, Antarctica), Ann. Glaciol., 51, 103-109, 2010.

Cuffey, K. M. and Paterson, W. S. B.: The Physics of Glaciers, 4th edn., Elsevier, Amsterdam, 2010.

Ghilani, C. D.: Adjustment Computations, Spatial Data Analysis, John Wiley and Sons, New Jersey, 2010.

Hambrey, M. and Lawson, W.: Structural styles and deformation fields in glaciers: a review, in: Deformation of Glacier Materials, edited by: Maltman, A. J., Hubbard, B., and Hambrey, M., Glaciological Society, London, Special Publications, 176, 147$157,2000$.

Hanson, B.: A fully three-dimensional finite-element model applied to velocities on Storglaciären, Sweden, J. Glaciol., 41, 91-102, 1995.

Hooke, R. LeB., Calla, P., Holmlund, P., Nilsson, M., and Stroeven, A.: A three-year record of seasonal variations in surface velocity, Storglaciären, Sweden, J. Glaciol., 35, 235-247, 1989.

Jay-Allemand, M., Gillet-Chaulet, F., Gagliardini, O., and Nodet, M.: Investigating changes in basal conditions of Variegated Glacier prior to and during its 1982-1983 surge, The Cryosphere, 5, 659-672, https://doi.org/10.5194/tc-5-659-2011, 2011.

Joughin, I, Smith, B., and Abdalati, W.: Glaciological advances made with interferometric synthetic aperture radar, J. Glaciol., 56, 1026-1042, 2010.

Martín, C., Navarro, F. J., Otero, J., Cuadrado, M. L., and Corcuera, M. I.: Three-dimensional modelling of the dynamics of Johnsons glacier (Livingston Island, Antarctica), Ann. Glaciol., 39, 1-8, 2004.

Molina, C.: Caracterización dinámica del glaciar Hurd combinando observaciones de campo y simulaciones numérica, $\mathrm{PhD}$ thesis, Universidad Politécnica de Madrid, 2014.

Molina, C., Navarro, F., Calvet, J., García-Selles, D., and Lapazaran, J.: Hurd Peninsula glaciers, Livingston Island, Antarctica, as indicators of regional warming: ice-volume changes during period 1956-2000, Ann. Glaciol., 46, 43-49, 2007.
Navarro, F. J., Otero, J., Macheret, Y. Y., Vasilenko, E. V., Lapazaran, J. J., Ahlstrøm, A. P., and Machío, F.: Radioglaciological studies on Hurd Peninsula glaciers, Livingston Island, Antarctica, Ann. Glaciol., 50, 17-24, 2009.

Navarro, F., Jonsell, U., Corcuera, M., and Martín-Español, A.: Decelerated mass loss of Hurd and Johnsons glaciers, Livingston Island, Antarctic Peninsula, J. Glaciol., 59, 115-128, 2013.

Oliva, M., Navarro, F., Hrbáček, F., Hernández, A., Nývlt, D., Pereira, P., Ruiz-Fernández, J., and Trigo, R.: Recent regional cooling of the Antarctic Peninsula and its impacts on the cryosphere, Sci. Total Environ., 580, 210-223, https://doi.org/10.1016/j.scitotenv.2016.12.030, 2016.

Osmanoğlu, B., Braun, M., Hock, R., and Navarro, F. J.: Surface velocity and ice discharge of the ice cap on King George Island, Antarctica, Ann. Glaciol., 54, 111-119, https://doi.org/10.3189/2013AoG63A517, 2013.

Osmanoglu, B., Navarro, F. J., Hock, R., Braun, M., and Corcuera, M. I.: Surface velocity and mass balance of Livingston Island ice cap, Antarctica, The Cryosphere, 8, 1807-1823, https://doi.org/10.5194/tc-8-1807-2014, 2014.

Otero, J., Navarro, F. J., Lapazaran, J. J., Welty, E., Puczko, D., and Finkelnburg, R.: Modeling the Controls on the Front Position of a Tidewater Glacier in Svalbard, Front. Earth Sci., 5, 29, https://doi.org/10.3389/feart.2017.00029, 2017.

Otero, J., Navarro, F. J., Martín, C., Cuadrado, M. L., and Corcuera, M. I.: A three-dimensional calving model: numerical experiments on Johnsons Glacier, Livingston Island, Antarctica, J. Glaciol., 56, 200-214, 2010.

Ramírez-Rodríguez, M. E.: Modelización de la deformación superficial en áreas volcánicas mediante la teoría de wavelets, Aplicación al Volcán Decepción. PhD Thesis, Facultad de Ciencias, Universidad de Cádiz, 2007.

Ren, J., Qin, D., Petit, J. R., Jouzel, J., Wang, W., Liu, C., Wang, S., Qian, S., and Wang, X.: Glaciological studies in Nelson Island, Antarctica, J. Glaciol., 41, 408-412, 1995.

Rignot, E. and Kanagaratnam, P.: Changes in the velocity structure of the Greenland Ice Sheet, Science, 311, 986-990, 2006.

Rodríguez Cielos, R. and Navarro Valero, F.: Continuous velocity model for Johnsons and Hurd glaciers from 1999 to 2013, with link to model results in shapefile and MS Excel format, Universidad Politécnica de Madrid, PANGAEA, https://doi.org/10.1594/PANGAEA.846791, 2015.

Rückamp, M., Blindow, N., Suckro, S., Braun, M., and Humbert, A.: Dynamics of the ice cap on King George Island, Antarctica: field measurements and numerical simulations, Ann. Glaciol., 51, 80-90, 2010.

Rückamp, M., Braun, M., Suckro, S., and Blindow, N.: Observed glacial changes on the King George Island ice cap, Antarctica, in the last decade, Global Planet. Change, 79, 99-109, https://doi.org/10.1016/j.gloplacha.2011.06.009, 2011.

Schellenberger, T., Dunse, T., Kääb, A., Kohler, J., and Reijmer, C. H.: Surface speed and frontal ablation of Kronebreen and Kongsbreen, NW Svalbard, from SAR offset tracking, The Cryosphere, 9, 2339-2355, https://doi.org/10.5194/tc-9-2339-2015, 2015.

Servicio Geográfico del Ejército (SGE): Livingston Island. Hurd Peninsula, (Scale 1:25000), Madrid, Servicio Geográfico del Ejército, 1991. 
Strozzi, T., Luckman, A., Murray, T., Wegmüller, U., and Werner, C.: Glacier motion estimation using SAR offset-tracking procedures, IEEE T. Geosci. Remote, 40, 2384-2391, 2002.

Strozzi, T., Kouraev, A., Wiesmann, A., Wegmüller, U., Sharov, A., and Werner, C.: Estimation of Arctic glacier motion with satellite L-band SAR data, Remote Sens. Environ., 112, 636-645, https://doi.org/10.1016/j.rse.2007.06.007, 2008.

Van der Veen, C. and Whillans, I.: Force Budget: I. Theory and Numerical Methods, J. Glaciol., 35, 53-60, 1989.

Wuite, J., Rott, H., Hetzenecker, M., Floricioiu, D., De Rydt, J., Gudmundsson, G. H., Nagler, T., and Kern, M.: Evolution of surface velocities and ice discharge of Larsen B outlet glaciers from 1995 to 2013, The Cryosphere, 9, 957-969, https://doi.org/10.5194/tc-9-957-2015, 2015.
Ximenis, L., Calvet, J., Enrique, J., Corbera, J., Fernández de Gamboa, C., and Furdàda, G.: The measurement of ice velocity, mass balance and thinning-rate on Johnsons Glacier, Livingston Island, South Shetland Islands, Antarctica, Acta Geológica Hispánica, 34, 403-409, 1999.

Ximenis, L., Calvet, J., García, D., Casas, J. M., and Sàbat, F. Folding in the Johnsons Glacier, Livingston Island, Antarctica, in: Deformation of Glacier Materials, edited by: Maltman, A. J., Hubbard, B., and Hambrey, M., Glaciological Society, London, Special Publications, 176, 147-157, 2000. 